\title{
Satellite measurements of cyanobacterial bloom frequency in the Baltic Sea: interannual and spatial variability
}

\author{
M. Kahru ${ }^{1, *}$, O. P. Savchuk ${ }^{2}$, R. Elmgren ${ }^{2}$ \\ ${ }^{1}$ Scripps Institution of Oceanography, La Jolla, California 92093-0218, USA \\ ${ }^{2}$ Department of Systems Ecology, Stockholm University, Stockholm 10691, Sweden
}

\begin{abstract}
Owing to the potentially harmful character of nitrogen-fixing filamentous cyanobacterial blooms in the Baltic Sea, a capacity to predict their occurrence is of interest. We quantified the surface accumulations of cyanobacteria, mainly Nodularia spumigena, using ocean colour satellite data. The spatial and temporal frequency of the accumulations was mapped with an automated detection algorithm, using their high reflectance in the 670 or $555 \mathrm{~nm}$ bands. Coastal Zone Color Scanner (CZCS) data were used for a first period (1979 to 1984), and combined SeaWiFS and MODIS-Aqua data for a second period (1998 to 2006). The frequency of cyanobacterial accumulations (FCA) for each $1 \mathrm{~km}^{2}$ pixel was calculated as the ratio of scenes with detected cyanobacteria to the number of valid cloud-free scenes in July-August. FCA varied greatly among years and the basins of the Baltic Sea. Mean FCA was $39 \%$ higher in the second period, but the increase was not statistically significant. The mean FCA for the whole Baltic was positively correlated with the residual phosphate (RP) concentration after the spring bloom in May-June. RP was a useful predictor of FCA in the coming summer, but could not predict the spatial pattern of the bloom. This was better explained by prevailing winds, with high FCA in the southwestern Baltic after northerly winds in July. It seems that, at the time of writing, useful FCA predictions can be made after the spring bloom, but only for the whole Baltic.
\end{abstract}

KEY WORDS: Cyanobacteria · Nodularia · Nutrients · Baltic Sea · CZCS · SeaWiFS · MODIS Resale or republication not permitted without written consent of the publisher

\section{INTRODUCTION}

Extensive summer blooms of diazotrophic cyanobacteria occur regularly in the Baltic Sea. They are of major environmental concern because they have the ability to add biologically useful forms of nitrogen to a eutrophicated but largely nitrogen-limited sea (Horstmann 1975), and are often toxic (Kononen 1992). Although cyanobacterial blooms have occurred in the Baltic Sea for at least 7000 yr (Bianchi et al. 2000), it is often suggested that their frequency and intensity have increased since the beginning of the 20th century owing to anthropogenic eutrophication. However, such an increase has been difficult to demonstrate conclusively at the scale of the Baltic Sea because of the intense patchiness of the blooms and the scarcity of reliable sea truth measurements (Finni et al. 2001).
Our knowledge of the environmental conditions controlling the occurrence and extension of cyanobacterial blooms, such as salinity, temperature, phosphorus availability during nitrogen limitation, wind impact and transport mechanisms, has been derived either from sparse monitoring data or from intensive but local studies (see e.g. Kononen et al. 1996, Wasmund 1997, Larsson et al. 2001, Laanemets et al. 2006, Rolff et al. 2007), and has not been sufficiently tested on interannual and basin-wide scales.

Cyanobacterial blooms in the open Baltic Sea are often dominated by the hepatotoxic species Nodularia spumigena Mertens. In well-developed blooms during calm weather, the buoyant $N$. spumigena filaments aggregate into dense surface accumulations, which are easily visible from space (Fig. 1A). The high 

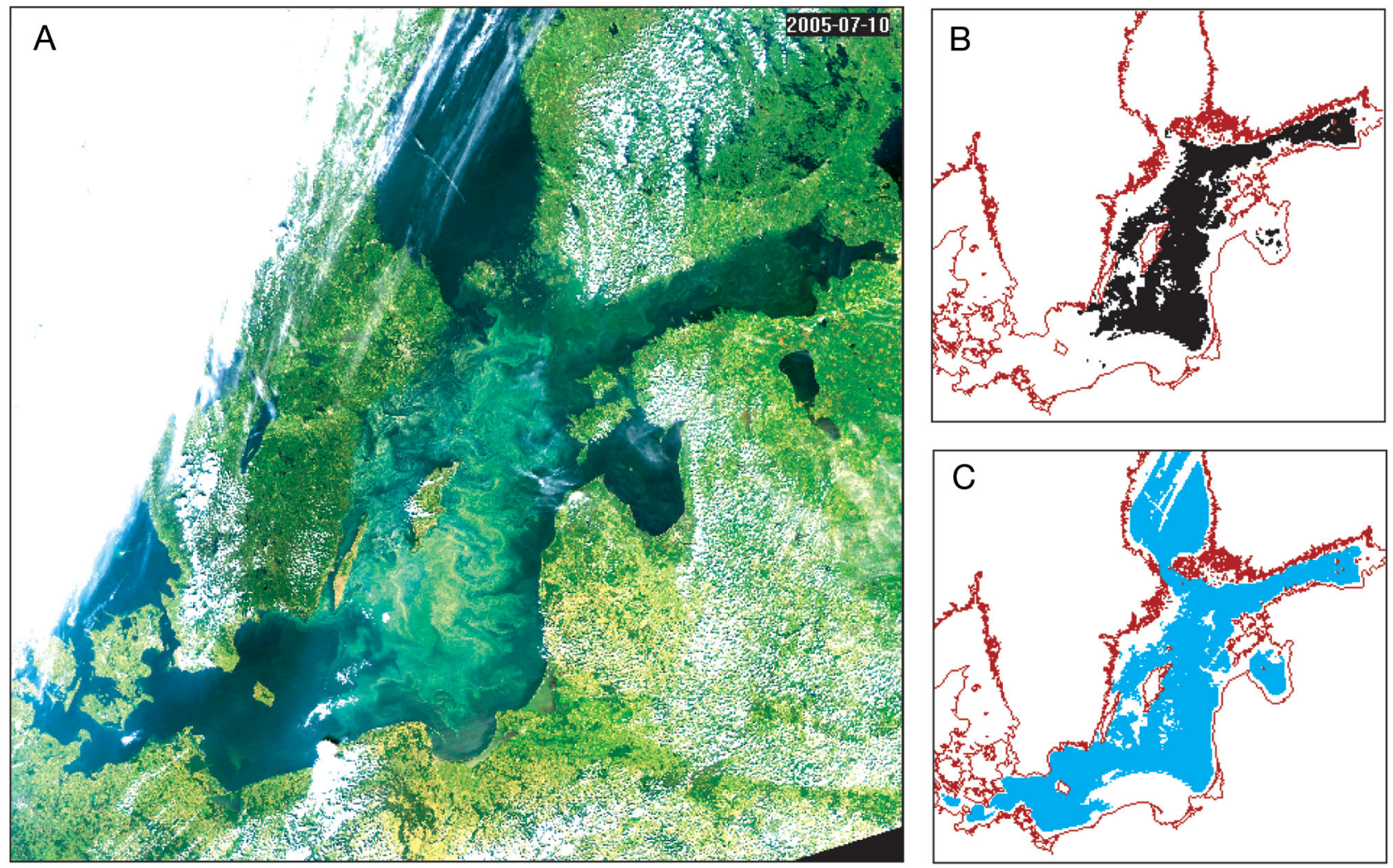

Fig. 1. Example of application of the detection algorithm. (A) Quasi-true-colour image produced from MODIS-Aqua bands 1 (red), 3 (blue), 4 (green) on July 10, 2005, showing cyanobacterial accumulations in the central Baltic and extending into the Gulf of Finland. Clouds (bright white) can be seen over both land and sea. (B) Detected cyanobacterial accumulations (black).

(C) Valid ocean areas (blue)

reflectance of the filaments at visible and near-infrared wavelengths is caused by the high refractive index difference between the gas vesicles and the rest of the cell. Baltic cyanobacterial accumulations were observed with early satellite sensors as early as the 1970s (Horstmann 1975, Öström 1976). Using satellite data from the Advanced Very High Resolution Radiometer (AVHRR) from 1982 to 1994, Kahru et al. (1994) and Kahru (1997) showed that such accumulations were particularly prominent in the periods 1982 to 1984 and 1991 to 1994, but detected no long-term trend.

Previous satellite-derived time series of cyanobacterial accumulations in the Baltic Sea (Kahru et al. 1994, 2000, Kahru 1997) used data from the AVHRR on the NOAA weather satellites, which had broad spectral bands, low sensitivity and poor calibration accuracy. The detection algorithm mainly used the high reflectance of the accumulations in the visible AVHRR band (570 to $700 \mathrm{~nm}$ ). Atmospheric correction and the derivation of water-leaving radiance from AVHRR data were not of sufficient accuracy to allow reliable unsupervised separation of cyanobacterial accumulations from other high-reflectance sources (clouds, bottom reflectance, haze, sun-glint, and suspended sediments).

In this study we instead used satellite data from specialized ocean colour sensors with bands that are spectrally narrower and more sensitive than those of the AVHRR. Much effort has been spent on accurate calibration and atmospheric correction algorithms of ocean colour sensors (McClain et al. 2006). While cyanobacterial accumulations are easy to observe using ocean colour sensors, no quantitative time series have yet been constructed using this data source. Ocean colour data were available from 15 summers, the period when cyanobacterial accumulations in the Baltic Sea mainly occur. The recently reprocessed Coastal Zone Color Scanner (CZCS) covers the period 1979 to 1984, and the combined SeaWiFS (1998 to 2004) and MODIS-Aqua (2002 to 2006) the later period of 1998 to 2006. We used these satellite data to illustrate bloom variability in time and space, to evaluate environmental conditions controlling bloom intensity at the basin-wide scale, and to explore the possibility of predicting 
bloom intensity, a capacity that would be useful for Baltic tourists, recreation and fishing industries, water quality managers, and scientists.

\section{MATERIALS AND METHODS}

In standard ocean colour data processing, the normalized water-leaving radiances $(n L w)$ are calculated for each band and a detailed characterization of each satellite pixel is performed using so-called Level 2 flags (McClain et al. 2006, see also http://oceancolor. gsfc.nasa.gov/DOCS/MSL12/). The algorithm for detecting cyanobacterial accumulations uses both the high $n L w$ and the Level 2 flags. Surface accumulations of cyanobacteria form characteristic patterns that are clearly distinguishable when they occur in the open sea in high concentrations (Fig. 1A). By visual comparison it was determined that accumulations are detected at $n L w(555 \mathrm{~nm})>0.8 \mathrm{~mW} \mathrm{~cm}^{-2} \mu \mathrm{m}^{-1} \mathrm{sr}^{-1}$. The same threshold was also applied to the very similar bands on MODIS-Aqua (551 nm) and CZCS (550 nm). The $555 \mathrm{~nm}$ band penetrates into the upper water column and also shows scattering in the top few meters. For example, the Oder Bank (southwestern Baltic proper, depth $\sim 8 \mathrm{~m}$ ) is commonly seen in $n L w$ (555) owing to its bottom reflection or suspended sediments above the bottom. The $555 \mathrm{~nm}$ band is also sensitive to turbid plumes, e.g. of suspended sediments, in shallow water and near river mouths. Because of the strong absorption of the $670 \mathrm{~nm}$ band by water, it does not penetrate as deeply into the water column, making $n L w$ (670) more sensitive to backscattering at or near the surface, e.g. owing to cyanobacterial accumulations. Thus, the Oder Bank and river outflows are normally not visible in $n L w$ (670). The $670 \mathrm{~nm}$ band gives an output more similar to the previous (Kahru 1997) time series using AVHRR Band 1 (580 to $680 \mathrm{~nm}$ ). Instead of directly using a threshold on $n L w$ (670) we used the turbid water flag, which corresponds to pixels with a remote sensing reflectance at $670 \mathrm{~nm}$ of $>0.0012 \mathrm{sr}^{-1}$ or $n L w(670)>0.18498 \mathrm{~mW} \mathrm{~cm}^{2}$ $\mathrm{nm}^{-1} \mathrm{sr}^{-1}$ (assuming an extra-terrestrial solar irradiance of $154.15 \mathrm{~mW} \mathrm{~cm}^{-2} \mathrm{~m}^{-1}$ corresponding to the MODIS $670 \mathrm{~nm}$ band). A series of other Level 2 flags were used to eliminate cloudy or questionable pixels. For example, the maximum aerosol iteration flag reveals if atmospheric correction is likely to have failed, as often occurs near cloud edges. Use of this flag eliminates many false positives. A pixel is evaluated for high reflectance (turbidity) only if it is classified as 'valid ocean', i.e. if none of the following flags are set: ATMFAIL, LAND, HIGLINT, HILT, HISATZEN, STRAYLIGHT, CLDICE, HISOLZEN, LOWLW, CHLFAIL, MAXAERITER, ATMWARN, or DARKPIXEL (for ex- planation of these flags, see http://oceancolor.gsfc. nasa.gov/DOCS/MSL12/). This eliminates clouds and other conditions in which the detection of cyanobacterial accumulations either is not possible or likely to produce erroneous results. For example, in Fig. 1A, accumulations can also be visually detected in the southeastern Baltic proper, but owing to the high sun glint the water-leaving radiances cannot be detected there with acceptable accuracy; therefore, the area was masked as not being valid ocean (Fig. 1C) and no accumulations were registered (Fig. 1B). This method works well for MODIS-Aqua data, but in SeaWiFS and especially CZCS data the errors in atmospheric correction sometimes caused obvious false positives, which were deleted after visual inspection.

All available Level 2 datasets from the period JuneAugust were downloaded from the NASA Ocean Color website (http://oceancolor.gsfc.nasa.gov/) and mapped to a standard Albers conic equal area projection with $1 \mathrm{~km}$ resolution. Shallow (<30 m) near-shore areas that are often turbid owing to suspended sediments were excluded (see Fig. 2), because cyanobacterial accumulations are difficult to reliably distinguish from other high-reflectance sources in near-shore areas. Because Nodularia spumigena blooms typically occur in the open sea (e.g. Wasmund 1997), the exclusion of the coastal zone did not greatly reduce the total detected bloom area.

Maps of accumulations and of valid ocean pixels detected on individual satellite scenes were composited into cumulative maps covering longer time periods. A cumulative map shows the number of times each pixel was counted (as an accumulation and/or valid ocean). From these cumulative maps we calculated the frequency of cyanobacterial accumulations (FCA), defined as the ratio of counts of detected cyanobacterial bloom scenes to counts of valid ocean scenes. FCA was calculated for each month, and individual months were then averaged to obtain an average FCA. Since cyanobacterial blooms are not known to occur in Bothnian Bay, this northernmost part of the Baltic Sea was excluded from all maps and calculations. Nodularia spumigena blooms typically occur from late June to the end of August (Kononen 1992, Kahru et al. 1994, Wasmund 1997), but FCA maps were produced as the average for the JulyAugust time period of each year because there were very few bloom observations for June. The number of satellite scenes available was much lower in the CZCS period (see Table 1). The years 1985 and 1986, when CZCS was still operational, had to be excluded because there were too few scenes from June-August. The highest number of scenes available were from the period 2002 to 2004, when both SeaWiFS and MODISAqua were in use (Table 1). FCA is calculated as the 
number of bloom pixels divided by the total number of valid data pixels, and is therefore expected to produce an unbiased estimate of the true frequency even with a relatively low number of scenes. This was not possible in earlier work with AVHRR because we could only calculate the cumulative accumulation area, which inevitably increases with the number of scenes available.

The photosynthetically available radiation (PAR) was obtained from one of the ocean colour sensors (SeaWiFS), and its mean was estimated for the areas of interest for the 1998 to 2006 period.

All operations with satellite data were handled with software from Wimsoft (http://wimsoft.com).

We computed time series of basin-scale volumeweighted averages from the data in the Baltic Environment Database using its Data Assimilation System (Sokolov et al. 1997) for the following quantities: RP, residual phosphate left in the surface 0 to $20 \mathrm{~m}$ layer after the spring bloom (calculated from the 3-dimensional phosphate fields reconstructed from measurements pooled together for May-June); WEP, winter excess of phosphate relative to the 'Redfield demand' (calculated as WEP = DIP - DIN/16 in the upper $50 \mathrm{~m}$ from February-March fields); SSWT, summer surface layer $(0$ to $20 \mathrm{~m})$ water temperature (calculated from July-August fields). Each of these individual 3-dimensional fields was reconstructed from several dozen to a few hundred oceanographic stations covering the studied domain.

Information on wind was obtained from NCEP reanalysis data available at www.cdc.noaa.gov. The frequency distribution of the wind direction and the average wind speed over eight $45^{\circ}$ compass sectors for every July and August between 1979 and 2006 were

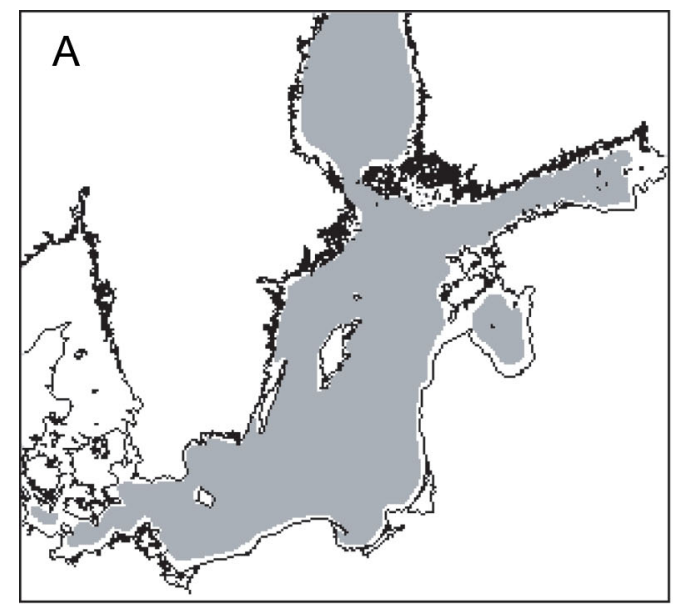

calculated from time series of $6 \mathrm{~h}$ data extracted for approx. $2^{\circ} \times 2^{\circ}$ grid nodes situated within the 9 studied basins (cf. Fig. 2).

\section{RESULTS}

The highest mean summer (July-August) FCAs for the whole Baltic Sea area as defined in Fig. 2A (i.e. excluding the shallow near-shore border) were registered in 1984, 1999 and 2005 (Table 1, Fig. 3). The mean FCA for July-August was $7.6 \%$ in the 1 st period (1979 to 1984 ) and $11 \%$ in the 2nd period (1998 to 2006), an increase in cyanobacterial blooms of $39 \%$. However, the increase is not statistically significant owing to the large variability among years.

At this whole Baltic Sea scale, RP was related to FCA by the regression equation $\mathrm{FCA}=85.13 \mathrm{RP}-2.85$ with a coefficient of correlation $\mathrm{r}=0.70(\mathrm{df}=13$; $\mathrm{p}=0.006)$, and hence was a useful predictor of bloom frequency (Table 1). Although at this scale there was a strong linear correlation between winter excess of phosphate (WEP) and RP $(r=0.85, d f=13 ; p=0.00012)$, the correlation of FCA with either WEP or summer temperature was only about $r=0.5$, i.e. much weaker than with $R P$, and not significant. Adding summer temperature to RP in the multiple linear regression $\mathrm{FCA}=68.715 \mathrm{RP}+$ 1.95SSWT -30.618 resulted in a predictive capacity of $r=0.78(\mathrm{df}=12 ; \mathrm{p}=0.006)$.

The spatial pattern of FCA (Fig. 4) varied greatly among years. For example, the highest summer FCA values were found in the southern Baltic in 2001 and 2006, but in the central and northern Baltic in 2003 and 2005. These patterns can be objectively decomposed into empirical orthogonal functions (EOF) and principal

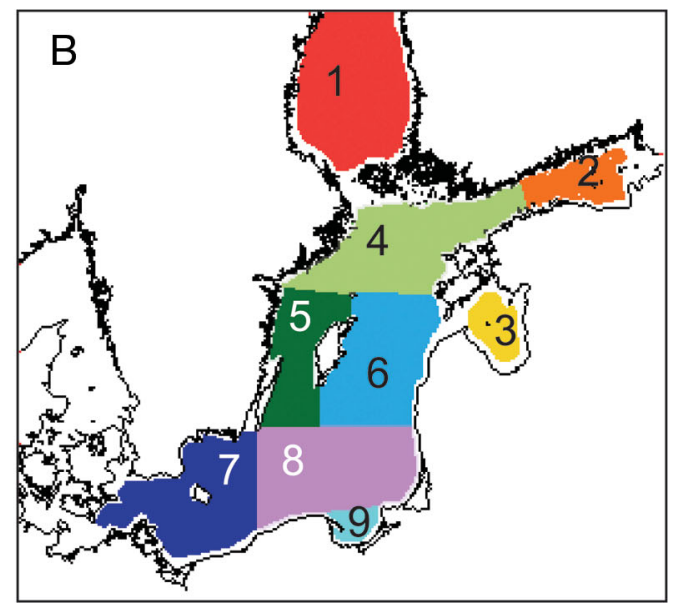

Fig. 2. Study areas in the Baltic Sea. (A) The area considered (grey) in mapping cyanobacterial blooms excludes near-shore areas with potentially high turbidity (white, $19.5 \%$ of the total sea area). (B) Partition into 9 separate basins: Bothnian Sea (BS, 1), Gulf of Finland (GF, 2), Gulf of Riga (GR, 3), Northern Baltic Proper (N BP, 4), Western Gotland Basin (W GB, 5), Eastern Gotland Basin $(\mathrm{E} \mathrm{GB}, 6)$, southwestern Baltic Proper (SW BP, 7), southeastern Baltic Proper (SE BP, 8), Bay of Gdansk (BG, 9) 
components. We applied EOF analysis only to the 2nd period, because the lower coverage of the first period could have biased the results. The first EOF $33 \%$ of the total variance) corresponded to a dipole pattern, with high FCA values alternating between the south-southwestern Baltic and the northern Baltic proper (Fig. 5A). High positive values of EOF1 (2001, 2006) correspond to high FCA in the south-southwestern Baltic, while negative EOF1 values (2002, 2003 and 2005) correspond to high FCA in the northern Baltic proper. EOF2 describes $27 \%$ of the total variance and cor-

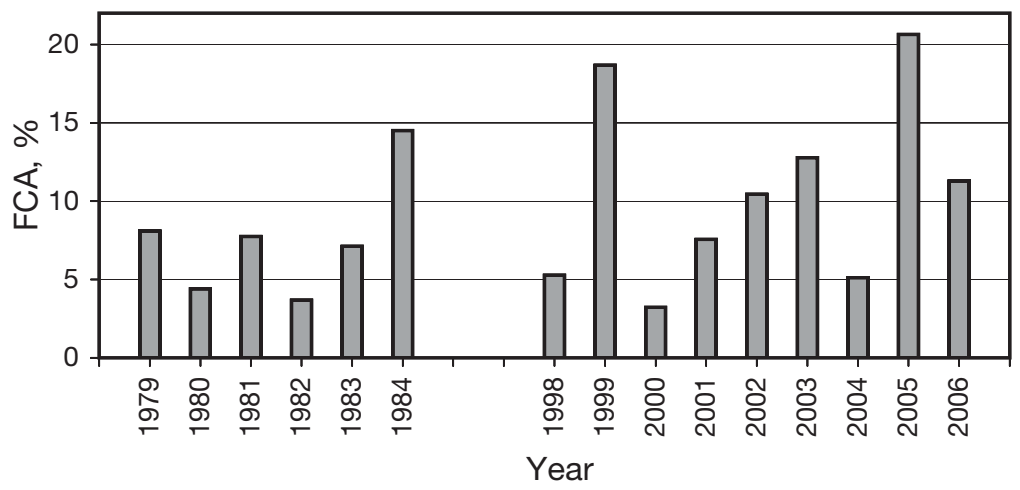
responds to a pattern of accumulations in the south-central Baltic (Fig. 5B). The first 2 EOFs describe $60 \%$ of the total variation.

Attempts to relate these spatiotemporal variations to the parameters that related most closely to FCA at the whole Baltic Sea scale were not successful. Coefficients of correlation between basin-wise FCAs and RP, WEP and SSWT were below $\mathrm{r}=0.5$ for all parameters and basins, except for SSWT in the Western Gotland Basin, southeastern Baltic Proper and Bay of Gdansk (Table 2), with WEP giving the weakest correlations. Basin-wise multiple regressions using RP and SSWT were slightly more successful ( $\mathrm{r}$ near or above 0.5), except for the outlying areas southwestern Baltic proper, Gulf of Riga and Bothnian Sea. Nevertheless, all regressions were below 0.5 for all basins combined, i.e. these factors cannot explain the interannual spatial variation in FCA seen in Fig. 3 and quantified by the EOF analysis (Fig. 5).

Table 1. Summary of satellite scenes used and of mean frequency of cyanobacterial accumulations (FCA) together with averages of in situ governing parameters. WEP, winter excess of phosphate; RP, residual phosphate; SSWT, summer surface layer water temperature

\begin{tabular}{cccccc|} 
Year & $\begin{array}{c}\text { No. of } \\
\text { scenes }\end{array}$ & $\begin{array}{c}\text { Mean } \\
\text { Jul-Aug } \\
(\%)\end{array}$ & $\begin{array}{c}\text { Mean WEP } \\
\text { Feb-Mar } \\
(\mu \mathrm{P})\end{array}$ & $\begin{array}{c}\text { Mean RP } \\
\text { May-Jun } \\
(\mu \mathrm{M})\end{array}$ & $\begin{array}{c}\text { Mean SSWT } \\
\text { Jul-Aug } \\
\left({ }^{\circ} \mathrm{C}\right)\end{array}$ \\
\hline 1979 & 25 & 8.1 & 0.21 & 0.11 & 14.1 \\
1980 & 34 & 4.4 & 0.13 & 0.11 & 14.8 \\
1981 & 21 & 7.7 & 0.25 & 0.15 & 14.1 \\
1982 & 16 & 3.7 & 0.21 & 0.10 & 14.7 \\
1983 & 30 & 7.1 & 0.31 & 0.13 & 15.4 \\
1984 & 13 & 14 & 0.58 & 0.21 & 15.0 \\
1998 & 87 & 5.3 & 0.20 & 0.12 & 13.9 \\
1999 & 111 & 19 & 0.19 & 0.12 & 16.9 \\
2000 & 97 & 3.2 & 0.29 & 0.10 & 15.0 \\
2001 & 97 & 7.6 & 0.19 & 0.09 & 16.3 \\
2002 & 229 & 10 & 0.30 & 0.15 & 17.1 \\
2003 & 264 & 13 & 0.29 & 0.20 & 16.8 \\
2004 & 263 & 5.1 & 0.40 & 0.17 & 15.5 \\
2005 & 150 & 21 & 0.56 & 0.24 & 15.8 \\
2006 & 138 & 11 & & & \\
\end{tabular}

An examination of basin-specific winds in July better explained the regional FCA patterns. As revealed by regression between basin-specific July FCAs in the southwestern Baltic proper and July wind statistics, cyanobacterial accumulations were negatively correlated $(\mathrm{r}=-0.58, \mathrm{df}=13 ; \mathrm{p}=0.03)$ to the prevailing (average frequency $28 \%$, mean speed $5 \mathrm{~m} \mathrm{~s}^{-1}$ ) westerly winds, while the rare and weaker (average frequency $6 \%$, mean speed $3 \mathrm{~m} \mathrm{~s}^{-1}$ ) northerly winds showed a stronger positive correlation $(\mathrm{r}=0.64, \mathrm{df}=13$; $\mathrm{p}=$ 0.013). In contrast, in the northern Baltic Proper, northerly and especially northwesterly winds were negatively correlated with FCA, with $\mathrm{r}=-0.56(\mathrm{df}=13$; $p=0.04)$ and $r=-0.71(d f=13 ; p=0.004)$, respectively. As examples, the high FCAs in the southwestern Baltic in 2001 and 2006 coincided with northerly wind occurring in $15 \%$ and $11 \%$ of all $6 \mathrm{~h}$ values in July, i.e. such winds were more common, and in addition stronger than normal. In contrast, the low FCAs in this area in 2003 and 2005 coincided with northerly wind frequencies in July of only $7.3 \%$ and $0.8 \%$, respectively, and with a lower than average speed.

Table 2. Coefficients of single and multiple correlations between basin-specific FCAs and related environmental characteristics (see Fig. 2 for basin definitions). WEP, winter excess of phosphate; RP, residual phosphate; SSWT, summer surface layer water temperature

\begin{tabular}{|lrrrrr|}
\hline Basin & WEP & RP & SSWT & $\begin{array}{r}\text { WEP \& } \\
\text { SSWT }\end{array}$ & $\begin{array}{c}\text { RP \& } \\
\text { SSWT }\end{array}$ \\
\hline BS & -0.07 & 0.06 & -0.05 & -0.09 & 0.08 \\
GF & 0.49 & 0.37 & 0.06 & 0.54 & 0.50 \\
GR & -0.44 & 0.12 & -0.27 & -0.68 & 0.28 \\
N BP & 0.26 & 0.43 & 0.32 & 0.36 & 0.46 \\
W GB & 0.16 & 0.49 & 0.50 & 0.50 & 0.56 \\
E GB & 0.02 & 0.48 & 0.47 & 0.48 & 0.58 \\
SW BP & 0.08 & 0.33 & 0.08 & 0.10 & 0.33 \\
SE BP & 0.15 & 0.45 & 0.60 & 0.61 & 0.74 \\
BG & 0.26 & 0.19 & 0.55 & 0.55 & 0.57 \\
Overall & 0.25 & 0.40 & 0.36 & 0.37 & 0.45 \\
\hline
\end{tabular}



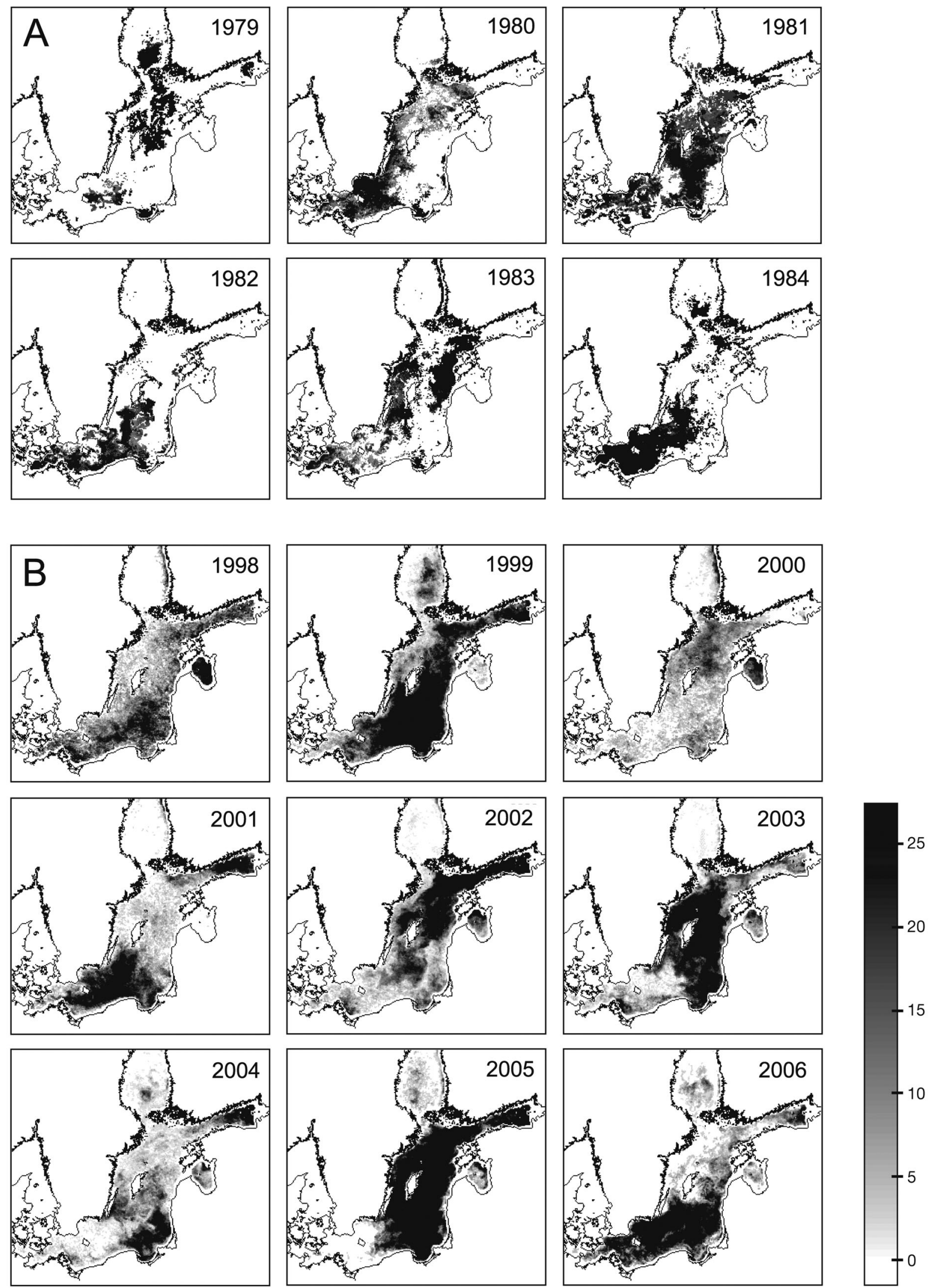

Fig. 4. Frequency (\%) of cyanobacterial accumulations for the July-August period. (A) 1979 to 1984. (B) 1998 to 2006 

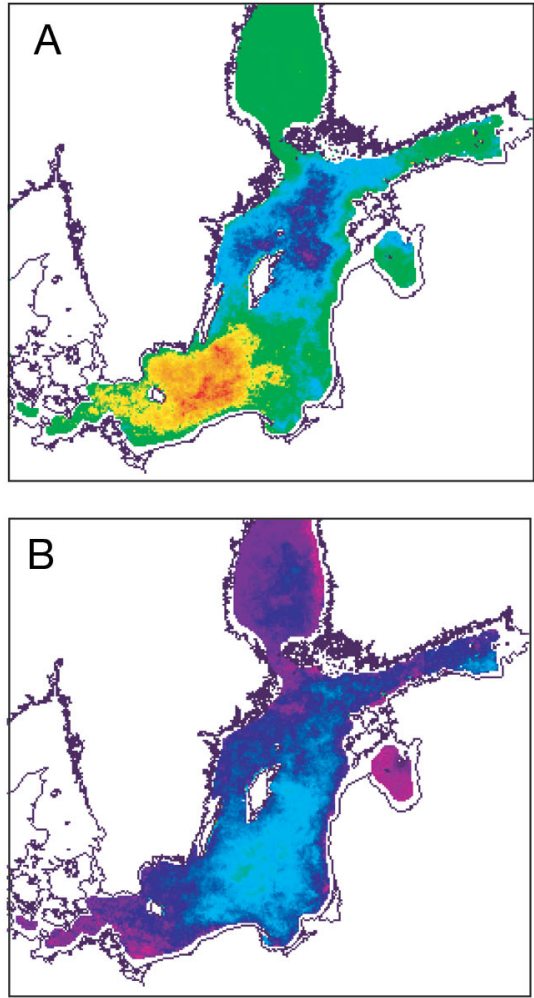

The total cumulative area of the accumulations is the total area of pixels in which accumulations were detected at least once during the season. During the 2nd period, the total cumulative area of accumulations was highest in 1999, at $200000 \mathrm{~km}^{2}$, and lowest in 2000, at only half that area (Fig. 6). The cumulative area increases with the number of satellite scenes available (Kahru 1997), making it a less reliable indicator than FCA of bloom variation among years. We therefore do not present cumulative areas for the 1st period, when there were far fewer satellite scenes available. Since FCA is less influenced by the number of satellite scenes available, we can use it to compare both periods (Fig. 3).

Monthly distributions of the FCA (Fig. 7) show that frequent accumulations occur in both July and August in some years (e.g. 1999), but are found almost exclusively in July in other years (e.g. 2005).

The frequency and extent of accumulations is known to correlate with surface irradiance (e.g. Kahru et al. 1994), and the mean FCA for the July-August period was positively correlated with mean PAR (FCA = 1.60PAR - 61.2, $\mathrm{r}=0.58, \mathrm{~N}=9$ ). Not surprisingly, PAR is also strongly correlated with $\operatorname{SSWT}(\mathrm{r}=0.96, \mathrm{df}=7$, $\mathrm{p}=0.00016)$. The summers of 1999 and 2005 stand out with FCAs that are even higher than expected from this correlation.

\section{DISCUSSION AND CONCLUSIONS}

The initiation of cyanobacterial blooms in the Baltic Sea has traditionally (Niemi 1979) been related to the low $\mathrm{N}$ :P ratio that results from the high concentrations of phosphorus in the low-oxygen or anoxic bottom layers (Niemistö et al. 1989, Kononen 1992). It is also known that high surface irradiance and a number of correlated variables (high sea surface temperature, high nearsurface stratification of the water column, low wind speed) are positively correlated with the intensity of cyanobacterial blooms and their accumulations at the surface (e.g. Kahru et al. 1994). The positive feedback of the cyanobacterial accumulations on the sea surface temperature indicated by satellite data (Kahru et al. 1993) was recently confirmed by a numerical model (Hense 2007). However, the large interannual differences in the extent and frequency of the accumulations in different sub-basins of the Baltic Sea has remained largely unexplained (Kahru 1997). As an exception, the re-occurrence of cyanobacterial accumulation in the Gulf of Finland starting in 1995 was related to the strong inflow of Kattegat waters into the Baltic Sea in late 1993 (Kahru et al. 2000). It appears that the complex interactions between the nitrogen and phosphorus cycles and other factors that lead to enhanced cyanobacterial blooms are hard to elucidate using the rather sparse and incomplete in situ data available (Vahtera et al. 2007). A numerical model has been used to show that the amount of excess phosphorus (WEP) rather than the N:P ratio itself is an important controlling factor (Kiirikki et al. 2001). Using a 3-dimensional ecosystem model, Janssen et al. (2004) showed that the North Atlantic Oscillation starts a chain of events that leads to increased wind stress, low ice cover in the winter, high mixed layer 


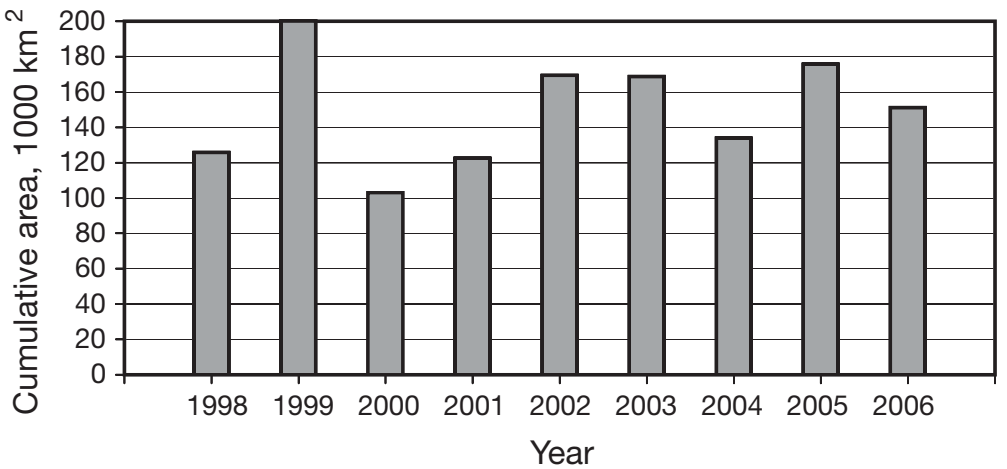

Fig. 6. Cumulative area of cyanobacterial accumulations in the Baltic Sea $\left(\times 1000 \mathrm{~km}^{2}\right)$

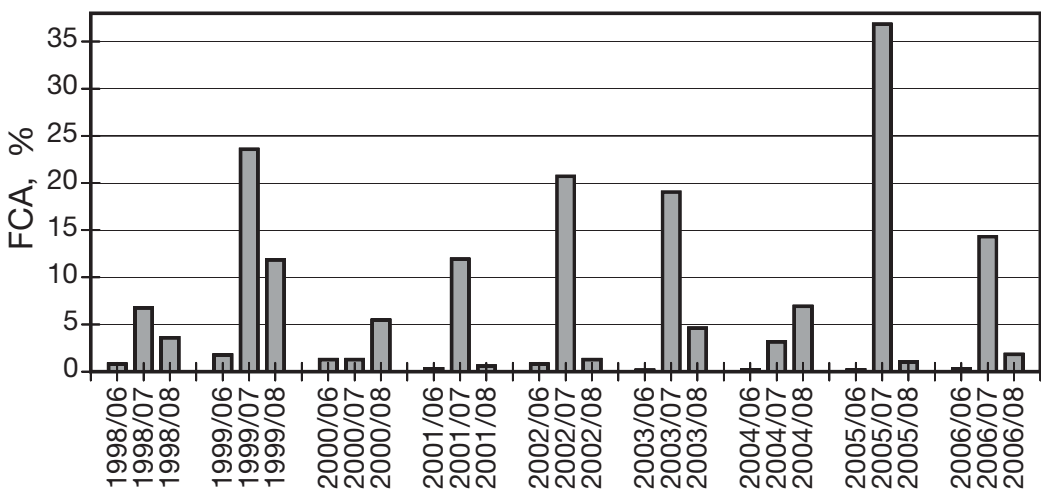

Fig. 7. Monthly frequency of cyanobacterial accumulations in the Baltic Sea for the 2nd period (1998 to 2006) (dates given as year/mo)

portion of Aphanizomenon sp. (formerly often identified as A. flos-aquae), which is often the dominant cyanobacterial taxon in the northern Baltic and a major nitrogen fixer (Rolff et al. 2007), and is distributed mostly at depth, unlike Nodularia spumigena, which is often concentrated at the surface (Hajdu et al. 2007). The detected accumulations will, however, mirror the extent of surface accumulations of $N$. spumigena, which are the major concern for the public and the tourist industry because of their toxicity and the often foul look and smell of such accumulations. For this reason, a capacity to predict bloom intensity weeks or months ahead would be useful. The residual phosphorus in spring was a reasonable predictor of bloom frequency in the following summer, but could not predict the spatial pattern of the bloom, especially the alterations in the southwestern Baltic. These seemed to be better explained by prevailing winds, with high FCAs following northerly winds. Because wind cannot be predicted long beforehand, useful FCA predictions can probably only be made after the spring bloom, and then for the Baltic as a whole. Closing the time gap of missing FCA observations between 1985 and 1997 could allow better predictive equations and determination of trends, as well as better

depth and strong upwelling, leading to high surface layer excess of inorganic phosphorus in the spring and eventually to a high cyanobacterial bloom intensity in the summer, given suitable weather conditions. This model explained some of the interannual variability in the extent and intensity of cyanobacterial blooms in the Baltic Proper observed by the satellite data from 1982 to 1993 (Kahru 1997). A complex modelling study emphasizing the positive and negative feedbacks between cyanobacteria and other factors (Hense 2007) indicated that cyanobacteria induce positive feedback effects as they grow, which may influence their interannual variations in abundance.

Here we used the detailed and more accurate data from satellite ocean colour sensors. The average frequency of cyanobacterial accumulations was $39 \%$ higher in the second period of observation (1998 to 2006) than in the first (1979 to 1984), but owing to the large variations and relatively short time period, the increase was not statistically significant. It should be noted that even ocean colour sensors do not penetrate deep enough to register cyanobacteria at depth in the upper mixed layer, and will thus miss a major inferences as to factors regulating the blooms. This would require using AVHRR data for the years that lack ocean colour sensor data, and careful intercomparison for years for which both types of data are available. Such a data series could perhaps also be useful for validating models of cyanobacterial bloom intensity in the Baltic Sea, which are an important element in long-term eutrophication modelling of the Baltic Sea.

Acknowledgements. Support was obtained from the Marine Research on Eutrophication (MARE) programme of the Swedish Foundation for Strategic Environmental Research (Mistra) granted to Fredrik Wulff, the Swedish Foundation Futura, and from Swedish Research Council funds granted to R.E.

\section{LITERATURE CITED}

Bianchi TS, Engelhaupt E, Westman P, Andren T, Rolff C, Elmgren R (2000) Cyanobacterial blooms in the Baltic Sea: natural or human-induced? Limnol Oceanogr 45: 716-726

Finni T, Kononen K, Olsonen R, Wallström K (2001) The his- 
tory of cyanobacterial blooms in the Baltic Sea. Ambio 30: $172-178$

Hajdu S, Höglander H, Larsson U (2007) Phytoplankton vertical distributions and composition in Baltic Sea cyanobacterial blooms. Harmful Algae 6:187-205

Hense I (2007) Regulative feedback mechanisms in cyanobacteria-driven systems: a model study. Mar Ecol Prog Ser 339:41-47

Horstmann U (1975) Eutrophication and mass occurrence of blue-green algae in the Baltic. Merentutkimuslait Julk/ Havsforskningsinst Skr 239:83-90

Janssen F, Neumann T, Schmidt M (2004) Inter-annual variability in cyanobacteria blooms in the Baltic Sea controlled by wintertime hydrographic conditions. Mar Ecol Prog Ser 275:59-68

Kahru M (1997) Using satellites to monitor large-scale environmental change: a case study of cyanobacteria blooms in the Baltic Sea. In: Kahru M, Brown CW (eds) Monitoring algal blooms: new techniques for detecting large-scale environmental change. Springer, Berlin, p 43-61

Kahru M, Leppänen JM, Rud O (1993) Cyanobacterial blooms cause heating of the sea surface. Mar Ecol Prog Ser 101: 1-7

Kahru M, Horstmann U, Rud O (1994) Increased cyanobacterial blooming in the Baltic Sea detected by satellites: Natural fluctuation or ecosystem change? Ambio 23: 469-472

Kahru M, Leppänen JM, Rud O, Savchuk O (2000) Cyanobacteria blooms in the Gulf of Finland triggered by saltwater inflow into the Baltic Sea. Mar Ecol Prog Ser 207:13-18

Kiirikki M, Inkala A, Kuosa H, Pitkänen H, Kuusisto M, Sarkkula J (2001) Evaluating the effects of nutrient load reduction on the biomass of toxic nitrogen-fixing cyanobacteria in the Gulf of Finland, Baltic Sea. Boreal Environ Res 6:131-146

Kononen K (1992) Dynamics of the toxic cyanobacterial blooms in the Baltic Sea. Finn Mar Res 261:3-36

Editorial responsibility: Howard Browman (Associate Editorin-Chief), Storebø, Norway
Kononen K, Kuoparinen J, Mäkele K, Laanemets J, Pavelson J, Nõmman S (1996) Initiation of cyanobacterial blooms in a frontal region at the entrance to the Gulf of Finland, Baltic Sea. Limnol Oceanogr 41:98-112

Laanemets J, Lilover MJ, Raudsepp U, Autio R, Vahtera E, Lips I, Lips U (2006) A fuzzy logic model to describe the cyanobacteria Nodularia spumigena blooms in the Gulf of Finland, Baltic Sea. Hydrobiologia 554:31-45

Larsson U, Hajdu S, Walve J, Elmgren R (2001) Baltic Sea nitrogen fixation estimated from the summer increase in upper mixed layer total nitrogen. Limnol Oceanogr 46: 811-820

McClain C, Hooker S, Feldman G, Bontempi P (2006) Satellite data for ocean biology, biogeochemistry, and climate research. EOS Trans Am Geophys Union 87:337

Niemi Å (1979) Blue-green algal blooms and N:P ratio in the Baltic Sea. Acta Bot Fenn 110:57-61

Niemistö L, Rinne I, Melvasalo T, Niemi Å (1989) Blue-green algae and their nitrogen fixation in the Baltic Sea in 1980, 1982, 1984. Finn Mar Res 17:3-20

Öström B (1976) Fertilization of the Baltic by nitrogen fixation in the blue-green alga Nodularia spumigena. Remote Sens Environ 4:305-310

Rolff C, Almesjö L, Elmgren R (2007) Nitrogen fixation and the abundance of the diazotrophic cyanobacterium Aphanizomenon sp. in the Baltic Proper. Mar Ecol Prog Ser 332: $107-118$

Sokolov A, Andrejev O, Wulff F, Rodriguez Medina M (1997) The data assimilation system for data analyses in the Baltic Sea. Syst Ecol Contrib 3:66

Vahtera E, Conley DJ, Gustafsson BG, Kuosa H and 7 others (2007) Ecosystem dynamics enhance nitrogen-fixing cyanobacteria blooms and complicate management in the Baltic Sea. Ambio 36:186-194

Wasmund N (1997) Occurrence of cyanobacterial blooms in the Baltic Sea in relation to environmental conditions. Int Rev Gesamten Hydrobiol 82:169-184

Submitted: December 4, 2006; Accepted: February 20, 2007 Proofs received from author(s): July 23, 2007 